\title{
The Discursive Struggles of the Client-Worker Relationship in the Social Services
}

\author{
Hanna Nykänen and Leena Mikkola \\ Department of Language and Communication Studies University of Jyvaskyla, Finland
}

\begin{abstract}
This study examines how disability service workers identify the discourses of the client-worker relationships. We studied the clientworker relationship from the perspective of the relational dialectics theory with a focus on relational contradictions and the meanings created within discursive struggles. We analyzed the interview data from 22 social workers using contrapuntal analysis. According to the social workers' perceptions, two discursive struggles exist in client-worker relationships: i) the struggle of integration, consisting of the contradiction of the ideal and the real and the contradiction of closeness and reservedness and ii) the struggle of certainty, consisting of the contradiction of predictability and novelty and the contradiction of openness and closedness. These struggles and contradictions arranges on the societal and relational frames to fully depict the nature of social work. Overall, our analysis shows that the client-worker relationship is both bound to the norms of a professional and a close interpersonal relationship, making its study particularly interesting.
\end{abstract}

\section{Introduction}

Social work is strongly client-based, and one of the main reasons that social workers choose this career lies in its focus on relationships with clients. ${ }^{1}$ Previous research on client-worker relationships in the social services sector indicated that clients view communication and interaction as important. They expect a friendship style of interaction and emphasize their wish for informality and the most appreciated social worker qualities are associated with respect, empathy, listening, and warmth. ${ }^{2}$ However, social workers have a wide variety of communication

Correspondence: Hanna Nykänen, Department of Language and Communication Studies, University of Jyvaskyla, P.O. Box 35 (Abuilding) FI-40014 University of Jyvaskyla

E-mail: hanna.k.nykanen@jyu.fi

Tel.: +358400630327

Key words: client-social worker relationships; contrapuntal analysis; relational dialectics theory; social services; interviews.

Conference presentations: This research has been presented in ICA $69^{\text {th }}$ international conference, Washington DC, USA, 26.5.2019.

Conflict of Interest: The Authors declare no potential conflict of interests.

Received for publication: 18 November 2019.

Accepted for publication: 6 June 2020.

This work is licensed under a Creative Commons Attribution NonCommercial 4.0 License (CC BY-NC 4.0).

${ }^{\circ}$ Copyright: the Author(s), 2020

Licensee PAGEPress, Italy

Qualitative Research in Medicine \& Healthcare 2020; 4:13-21

doi:10.4081/qrmh.2020.8688 styles and skills. ${ }^{3}$ For example, child and family social workers appear to use a confrontational style of communication in which a lack of empathy is typical. ${ }^{4}$

In addition to challenges with communication skills, client-worker relationships include various tensions due to the nature of social work. Client-worker relationships in the social services sector are affected by different kinds of power and dependency relations and pressures related to welfare and justice. ${ }^{5}$ Furthermore, social workers experience a high degree of role ambiguity and role conflict, which manifest in discrepancies between ideal and actual work outcomes. ${ }^{1}$ In addition, social workers have a difficult time avoiding being viewed as the other, as well as effectively making themselves understood. ${ }^{6}$ Negative images and uncertain identities ${ }^{7}$ harm their cooperation with clients and are associated with burnout and dissatisfaction with their work, ${ }^{8}$ threatening social workers' well-being. Additionally, tension between the philosophy of social work and growing work demands, ${ }^{1}$ such as the value conflict between anthropocentrism and managerialism, ${ }^{7}$ may hinder the client-centered approach of the service.

Previous research ${ }^{1-7}$ has clearly shown the challenges and tensions of social work, but how this paradoxicality is manifested in the client-worker relationship has not yet been studied. The tensions may lead to challenges in the collaborative client-worker relationship, which aims not only to support clients' welfare but also to offer workers opportunities to achieve personal accomplishments.

The current study takes a Relational Dialectics Theory $(\mathrm{RDT})^{9}$ approach to describe how relational contradictions of client-worker relationships are manifested in the talk of disability service workers. We pursue this aim by identifying discourses and analyzing the types of meanings that are created in the interplay of these discourses. ${ }^{9}$ Specifically, we observed client-worker relationships from an RDT perspective and concentrated on contradic- 
tions in these relationships to identify relationship-based tensions and the meanings of the relationships that are constructed in the interplay of these tensions.

\section{Theory}

RDT is Baxter and Montgomery's ${ }^{10}$ theory of relational meaning making, which explains how the identity of an individual and his/her interactive relationships are built through language. Baxter's ${ }^{9}$ elaborated and remodeled the theory, RDT 2.0 , guides the rationale for this study. The theory is based on Bakhtin's ${ }^{11}$ ideas about dialogism and the creation of meanings through the interaction of competing and often opposing discourses. In this study, we refer to discourse as a meaning system - that is, a set of claims and suggestions that combine to form a particular meaning. Contrary discourses, in turn, form contradictions. $^{9}$

Baxter and Montgomery ${ }^{10}$ identified three main contradictions that appear in relationships: i) the contradiction of autonomy-connection refers to the tension between aims for independence and demands for integration, ii) the contradiction of novelty-predictability consists of seeking novelty while simultaneously trusting the safety of stability, and iii) the contradiction of openness-closedness refers to simultaneously sharing information and trying to require privacy from others. Baxter and Montgomery ${ }^{10}$ defined the contradictions as discourse pairs that are inherent in all social life. Thus, they are not interpersonal conflicts, they are not charged positively or negatively, and they do not require resolution.

Contradictions are always present, and, when we balance them, we create meanings. RDT is an interpretative theory that offers alternative perspectives for communicative phenomena compared to positivist theories, which aim for predictability. In this theory, the key focus shifts away from the individuals and focuses on the interaction and language of the relationship parties. ${ }^{9}$

According to Baxter, ${ }^{9}$ the contradictions formed by discourses are discovered in language utterance chains, which consist of individual utterances. Each utterance is built on an interface between the past and the present. The distal already-spoken dimension links the utterance to the existing discourses of a larger culture. The proximal already-spoken dimension links the utterance to what has been said in this specific relationship, affecting how statements are expressed and interpreted. The construction of utterances is also influenced by anticipation of the party's acceptance both in this specific relationship (proximal not-yet-spoken) and outside the relationship in the form of societal responses (distal not-yet-spoken). All of these dimensions thus influence how utterances are formed, as well as how meanings are generated through interaction.

Power is a significant actor in RDT. ${ }^{9}$ However, power is a feature of the discourse rather than a feature of the actors in the relationship. Power is perceived by analyzing how strong discourses are conveyed in the text. It is perfectly normal that the discourses in the text are not equally strong but are partly centripetal and partly centrifugal. Baxter ${ }^{9}$ explained that a discourse takes a centripetal position when it is given greater power or importance; in other words, the discourse is accepted as normative or natural. When a discourse is given a less powerful and marginalized position, it is considered to have a centripetal role and is categorized as unnatural.

RDT was developed and has mostly been used to study close relationships, ${ }^{12,13}$ although it has been applied to health services research in a few studies, ${ }^{14-19}$ which primarily focused on roles and relationships involving doctors, patients, and nurses. Health care relationships include many challenging interactions, and understanding their relational contradictions is important in order to develop communication. Closeness is an essential part of the health care relationship; this is especially true in challenging situations, where balancing becomes harder and emphasis easily shifts towards distance. ${ }^{14}$ In addition, contextual factors may create contradictions, which then interpenetrate ${ }^{10}$ the relational contradictions experienced in interpersonal relationships. ${ }^{15}$

The topics of interaction in the health care context are sometimes tough. Studies demonstrate the applicability of relational contradictions in the context of end-of-life communication in order to provide physicians with improved communication skills to address the challenges that dealing with death produces in their client-worker relationships. Amati and Hannawa ${ }^{16}$ noted that relational contradictions are always present in client-worker interactions; they also identified new contradictions, such as desire versus ability and standardization versus personalization, and authenticated the three original contradictions of autonomy-connection, predictability-novelty, and openness-closedness.

In addition to challenging topics of interaction, workload and pressure also create tensions in client-worker relationships in health care settings. For example, physicians in Emergency Departments (EDs) favor efficient communication at the expense of comprehension or rapport; this is understandable due to the fast-spaced nature of EDs, but it does not support the idea that patientcentered perspectives are usually the main objective of health care relationships. ${ }^{17}$

Challenges occur also in client-worker discussions of diabetes management. O'Hara and Shue ${ }^{18}$ studied the client-worker relationship by analyzing diabetes management discussions between patients and physicians. They realized that understanding these discourses and their interplay helps physicians focus on the cultural discourse that shapes their own and their clients' views of diabetes management, as well as notice the transformational possibilities that can occur in treatment plan discussions. In addition, Peltola and Isotalus ${ }^{19}$ explored competing discourses in type 2 diabetes management by analyzing pa- 
tients' descriptions of interactions with their health care professionals. They found a new struggling discourse pair-having the right to care versus deserving carewhich had not previously been emphasized as a central contradiction.

Although applications in the health care context indicate that RDT is suitable for describing and explaining client-health care provider interactions and relationships, and although there is evidence of a different kind of contradiction in client-worker relationships in the social services sector, ${ }^{5}$ RDT has not been applied in the context of social services. The only themes covered by RDT from the social services point of view have been adoption and foster families. ${ }^{20-22}$ Those studies researched the discursive construction of family but did not emphasize the relationship between the client and the worker.

In the present study, we explore the relational contradictions of the client-worker relationship in the context of disability services. The relationship is interesting to explore using RDT because it is a long-term dependencybased relationship, which includes many pressures, such as controlling versus helping, in its basic nature. Moreover, to achieve successful collaborative relationships, social workers need to identify interpersonal contradictions and learn to manage them.

\section{Aim of the Study}

This study aimed to understand the social construction of the client-worker relationship in disability services by identifying what kinds of related discourses disability service workers manifest in their talk. We study the clientworker relationship from the RDT perspective, which concentrates on relational contradictions and the meanings created in those discursive struggles. The Research Questions (RQs) are as follows:

i) RQ1: What competing discourses, if any, social workers' present in their talk about client-worker relationships?

ii) RQ2: What kinds of meanings regarding the identity of these relationships the competing discourses create?

Answering the first question involved analyzing interview data and identifying various discourses that manifested in the social workers' talk. Answering the second question entailed a continuation of the analysis process by elaborating how the discourses interacted with each other, as well as what kinds of meanings the interplay creates. RDT provided insights into how the meaning of the social workers create the identity of the client-worker relationship in their talk.

Communication practices constitute relationships, and the communication parties author selves in the interaction. ${ }^{23}$ The client-worker relationship, in this study, is a professional relationship between a disability service worker and a disabled client or his/her next of kin, which functions as a service and counselling relationship.

\section{Materials and Methods}

\section{The Context}

In Finland, the Ministry of Social Affairs and Health is responsible for promoting the health and well-being of people with disabilities, developing the tightly interdependent totality of social and health care services, and securing each client's livelihood. Various laws, such as the Social Welfare Act, stipulate disability services. Rights to equality, participation, and necessary services and support are the three principles of the Finnish policy concerning individuals with disabilities. The aim of the Finnish disability policy is to support the autonomy and agency of individuals living with disabilities. Municipalities organize and finance services and support for everyday life. Social workers develop a personal service plan for clients and make decisions regarding the services and support that the clients need, such as transportation services and personal assistance. ${ }^{24} \mathrm{~A}$ social worker is assigned to a client based on the region in which the client lives. The client cannot choose the person with whom he/she works.

\section{Data}

We interviewed social services workers from two different organizations for a total of 22 interviews. This was a two-researcher study, the first author carried a main responsibility of the interviews. The first data set consisted of 12 in-depth interviews ${ }^{25}$ of social service workers from the same disability services unit. The length of their careers ranged from a couple of months to 20 years. One participant was male, and 11 were female.

We asked open-ended questions, such as how would you describe your work/client relationships? In addition, participants provided examples about various situations at work and with clients. Themes about successful/unsuccessful interactions, general reasons for meeting clients, receiving feedback, instructions for working with clients, power relations, client expectations, conflicts, and ethical concerns were discussed. In addition, we also provided questions about peer and supervisor relationships.

After conducted the first dataset, we transcribed and coded it, and afterwards gathered the second one. The second data set consisted of 10 in-depth interviews of social workers from a different disability service organization. Their careers varied from a couple of years to dozens, but all of the participants had only worked in their current unit for a couple of years. Most of them had a long history of working with disabled clients. All of the participants were female.

First author conducted also the second set of interviews and she asked the same open-ended questions as in the previous set, along with questions derived from the earlier analysis to determine whether the social workers recognized the contradictions that emerged from the first data set. We did not directly name the contradictions in 
the questions; but instead described the themes and asked the social workers to give examples of interactional situations with clients in which they identified the specific theme and how they felt it affected the client-worker relationship.

Interviewees decided whether they want to give the interview in the meeting room of social services office or on campus at the university. The interviews took anywhere from 40 to 85 minutes, varying with each participant. The average duration was 55 minutes. We transcribed all the interviews verbatim, yielding 283 pages of transcribed text with Lato font and line spacing set at 1.07.

\section{Method of Analysis}

We chose to analyze the data using contrapuntal analysis, ${ }^{9}$ which is a form of discourse analysis related to RDT 2.0. According to Baxter, ${ }^{9}$ the key focus of contrapuntal analysis is the interaction of competing discourses, while basic units of interaction, utterances, and utterance chains lie at the core of the analysis. This analysis makes interaction-based discourses visible so that the researcher is able to understand how discourses are maintained, how they construct meaning, and how the balance among discourses affects the client-worker relationship.

Discourses can interact through diachronic separation or synchronic interplay. ${ }^{9}$ In diachronic separation, the dominance of the discourse changes through different periods of time or the power of the discourse varies within different contexts or themes. In synchronic interplay, there is a co-occurrence of multiple discourses in a given period of time; an example of this kind of interplay is a non-antagonist struggle in which multiple discourses are identified in actors' utterances. According to Baxter, ${ }^{9}$ a non-antagonist struggle is common for interview data in which one party of a relationship constructs the meaning of the relationship. Three different discourse markers may help identify competing discourses in a text: negating (denying one discourse entirely), countering (replacing the obvious discourse), and entertaining (indicating that the given discourse is only one of many possibilities). ${ }^{9}$

\section{Conducting the Analysis}

The first author coded the data and conducted the analysis of the interplay of the discourses, however together we critically discussed all interpretations to strengthen the credibility of the analysis. The analysis was initiated by importing the transcribed interview data into the Atlas.ti application. The interviews of the first data set formed an entirety, which was rationalized because the key focus of this study is understanding how contradictions in the client-social worker relationships were manifested in the utterances of social service workers. Therefore, all of the contradictions interpenetrate utterances appearing in the data as a whole instead of focusing in one interviewee's utterances.
First, the first author coded the text multiple times to determine possible initial coding categories related to the client-worker relationship. ${ }^{26}$ We then captured what was said in the text and what was indicated by the relationship's identity by initial coding categories that consisted of meanings that we combined into semantic themes, as in discourses. For example, the sentence: It was so clear to me that I am here for the clients was coded as integration (initial coding) and categorized into the semantic theme of closeness.

Second, after identifying the semantic themes, we initiated an in-depth analysis of interplaying discourses. This part of analysis the first author conducted by exploring whether multiple discourses were present in the text and, if so, whether they had any interplay with each other. The analysis of the interplay meant identifying the discursive markers ${ }^{9}$ as negating, countering, or entertaining. In the example below, the word but reveals the interplay. This example we labelled as synchronic interplay that led to a non-antagonist struggle.

And the other one [client] is over the moon like this is awesome. Although their child got diagnosed and will not get better, they will have this kind of worker who they can use and turn to, and this worker will support them and helps them when necessary. But, then we have these [clients] who just make calls [saying] that do not come here.

For the second dataset, we focused the analysis on the interplay presented around the already identified discourses. The next example is an excerpt in which a social worker described how distance and closeness resonated in his/her client relationship. The social worker presents the working role itself as being generally distant and something that the worker did not want to be seen.

It is really important to me that the client relationship works and I am seen [as something] other than [an] authority [figure]. Of course, [I want to be seen] as [a] professional, but [also] as [a] human, not that you are going to see just some auntie social worker. In the service plans, I am using suitable language, but many of them cannot read so I'm trying to use [language in] ways [so] that it does not feel like a cold review message but that there is some kind foreword and flower or something.

The coding did not proceed as linearly as described because analysis is a recursive process. ${ }^{26} \mathrm{We}$ coded the data multiple times in order to obtain an effective hold on the totality of the data and understand the meanings constructed in the interplay of the contradictions, as well as the discourses forming the contradictions. All of the interview examples presented here and in the results section, we have carefully translated from Finnish to English while striving to maintain the original tone and meaning.

Ethical council of University of Jyväskylä has approved the research plan. The researchers have followed the ethical principles ${ }^{27}$ throughout the study, including re- 
specting the integrity of the subjects and providing extensive information about the study prior to the data collection process. Participation was voluntary, and the participants provided written consent to the researchers so that their interview data could be used for research purposes. To support the credibility of the results, we have presented examples of the interviews. In the discussion section, we will indicate how previous research compares with our results.

\section{Findings}

According to the social workers' talk, their clientworker relationships consisted of four contradictions: i) ideal-real, ii) closeness-reservedness, iii) predictabilitynovelty, and iv) openness-closedness. These four contradictions, in turn, formed two discursive struggles, as described in Table 1: i) the struggle of integration, consisting of the contradiction of ideal and real and the contradiction of closeness and reservedness and ii) the struggle of certainty, consisting of the contradiction of predictability and novelty and the contradiction of openness and closedness.

Table 1 also illustrates how these contradictions were arranged in regard to the societal frame and the relational frame to describe the balancing of close interpersonal and professional relationships. The frames link to the idea of the proximal and distal sites of the utterances. However, they are not referring to the strategy of reframing. ${ }^{9}$ In the societal frame, the main influence on contradictions originates from outside the client-worker relationship, meaning that the utterances appear to be in the distal already-spoken dimension. The struggles are largely societally constructed based on the context in which the relationship occurs. Society sets the rules and limits for the relationship and guides its aims and functions. In the relational frame, contradictions rely more heavily on the interaction between the two parties in the relationship. These struggles are present when social workers describe communication in client-worker relationships. We label the struggles here as contradictions of the proximal already-spoken dimension, although they are only retrospectively described by one party of the relationship.

\section{The discursive struggle of integration}

The struggle of integration emphasizes manifestations of the creation of a rewarding cooperative relationship. Table 2 presents the meanings of expected identity/otherness and supportiveness/facelessness created in struggle of integration.

\section{Societal frame}

The discursive struggle of integration emerges in the competition between discourse of the ideal and discourse of the real. This contradiction supports the meanings of expected identity or detracts from expectations creating otherness when actors' goals are authenticated or diminished, respectively. The contradiction is linked to the explicated mission of the social services sector, which is the provision of care. However, when social workers attempt to support the welfare of their clients, the workers may also constrict their clients' freedoms and rights since the system, the budget, and the law set the boundaries on what and how much help can be provided. Client and worker expectations concerning the nature of the relationship are not always aligned with the real. This contradiction causes tension concerning reciprocal appreciation in which clients conclude that social workers are violating or ignoring their civil rights, and social workers are uncertain about their career identities when they are unable to help.

This contradiction of ideal-real possesses features of Baxter and Montgomery's ${ }^{10}$ contradiction of autonomydependency. The system provided by society is expected to help clients achieve as autonomous a life as possible even though the clients are truly dependent upon social services. In some cases, the system makes the clients even more dependent upon the services than is necessary. A constant battle is thus waged between helping but not restricting and seeking help while remaining independent. The examples below demonstrate how social workers describe the non-antagonist struggle ${ }^{9}$ between the ideal and the real by showing various semantic positions in their ut-

Table 1. Struggles, contradictions, and frames.

\begin{tabular}{lll}
\hline & Societal Frame & Relational Frame \\
\hline Integration Struggle & Ideal-real contradiction & Closeness-reservedness contradiction \\
\hline Certainty Struggle & Predictability-novelty contradiction & Openness-closedness contradiction \\
\hline
\end{tabular}

Table 2. The constructed meanings in the discursive struggle of integration.

\begin{tabular}{lll}
\hline Contradiction & Frame & Constructed meaning \\
\hline Ideal-real & Societal & Expected identity/otherness \\
\hline Closeness-reservedness & Relational & Supportiveness/facelessness \\
\hline
\end{tabular}


terances. For example, use of the phrase I should see, indicates that there is also a possibility that the social worker's decision is not the best one for the client:

I go to the client's home, and there we think and see what is the client's need for the day. What is the thing we should be doing? And because, they are people who need special support, I, as a worker, should see what is beneficial for the client and what is good, although he wouldn't himself see it the same way as I do.

Antagonist struggles were also shared by social workers when they described challenging situations in which clients' expectations truly differed from reality:

Yes, the situation still is that the mother feels that the society cannot support them enough, although they have a really strong [set of] services already. Nevertheless, no services can be tailored so that they could be totally individualized. There are always specific borderlines.

When discussing the burdensome characteristics of social service workers' duties, there were also hints at a serious-playful struggle. A serious-playful struggle emphasizes the tone of the utterances. In this struggle, the social workers created a meaning of their own management skills to protect their reputations. In the example below, the interviewee acknowledged that sometimes the feedback he/she receives is rough while simultaneously diminishing that roughness with laughter, exemplifying the serious-playful struggle:

$\mathrm{Hmm}$, sometimes it gets under my skin so that I, as a person, feel bad, but most of the time I can take it. It just goes with the career, this kind of [situation] (laughing) that you can face anything. [It] go[es] in one ear and out the other, [as] if it is groundless. Otherwise, you cannot cope with this.

\section{Relational frame}

In the relational frame, the struggle of integration consists of the contradiction of closeness-reservedness. The social workers demonstrated this contradiction by describing their interactions with their clients, including longing for more personal conversations in which they might chat, lighten the atmosphere, and boost the collaboration. Closeness helps the social service workers endure rough working days and makes the interactions more pleasant, which may encourage cooperation. In other words, relational closeness creates meanings of supportiveness.

Meanwhile, reservedness was an essential element of the relationship. A client and a social worker do not have an intimate relationship; although their aim is to work together to help the client, a state of formality is retained. Face-to-face meetings and laws used in decision making create a huge gap between the discourse of closeness and reservedness, which, in turn, creates meanings of facelessness. The segmenting ${ }^{9}$ of closeness and reservedness is illustrated in the following example, in which a worker describes how the closeness of the previous interaction made the official part of the work - the decision making-harder. Reservedness helps social workers to stay objective in order to produce equal decisions, and not to admit any more to that client than you do to another client:

Like I have said, the equality, when it feels that sometimes you find the connection with the client straight away. Then, you have to be really careful because you cannot admit any more to that client than the S-client [inappropriate phrase].

The social workers noted that closeness and reservedness are both needed, but the discourse of reservedness becomes more powerful - and centripetal — when they are declining clients' applications.

\section{The discursive struggle of certainty}

The struggle of certainty emphasizes manifestations of certainty in the relationship. The dynamism of society creates uncertainty about the context in which the relationship operates, and challenges related to openness bring a cautious factor to the interaction and communication between the client and the social services worker. These struggles create the meanings of dynamism/stability and understanding/insensitivity like presented in Table 3 .

\section{Societal frame}

The discursive struggle of certainty illustrates the dynamic societal context of the relationship that the contradiction describes as predictability-novelty. The contradiction of predictability and novelty creates the meanings of the stability or dynamism nature of the relationship.

Society is changing, and all kinds of reforms are remodeling the social and health services. Laws change the requirements for the provided services, and the addition of new clients with different disabilities begin to challenge the functionality of the system. Social service workers must constantly learn new approaches and methods to stay up-to-date and work hard to find suitable services to help new clients. Dynamism also brings challenges in terms of offering equal service to everyone, which is one of the

Table 3. The constructed meanings in the discursive struggle of certainty.

\begin{tabular}{lll}
\hline Contradiction & Frame & Constructed meaning \\
\hline Predictability-novelty & Societal & Dynamism/stability \\
\hline Openness-closedness & Relational & Understanding/insensitivity \\
\hline
\end{tabular}


main aims of social work. In the following example, the social worker states that all the changes of society, law and work makes it harder to follow consistent line while making decisions and working with the clients.

Yes, indeed [changes affect our work]. I have thought about it and leaned on other[s] when trying to find the consistent alignment with the decisions made. We are not an old organization, but we should have consistent lines, at least within this area. But, even that is impossible, because the implementation methods differ in [the] municipalities. And we have discussed that disability services are like no other. Many things have to be interpreted from the law, and we have to use a lot [of] individual consideration. A lot more than in some other areas. Their lines are clearer.

\section{Relational frame}

Social workers talk about the openness-closedness contradiction when describing complex situations, leading to misunderstandings. Misunderstandings can be caused, for example, by the lack of a mutual language and shared meanings or difficulties in interpreting the law because, although the law is strong and understandable, the decisions are still based on interpretations, and some client cases are not so distinct. A mutual language refers to both an actual language, such as if clients have problems with speech production, and the language of bureaucracy. These struggles create meanings of understanding, but they also create insensitivity. Openness deals with reciprocal information sharing, which is required for successful cooperation. Social workers must balance how much information is sufficient for everyone, which details clients need or would like to hear, and how to reach all clients:

Often, in the beginning of the new client [relation]ship, they ask a very wide question: To which [services and support] I am entitled? There, you really have to watch your words, [especially] when you go through what the client needs to manage independently or as independently as possible.

In addition to a non-antagonist struggle, these discourses also possess a direct-indirect struggle in which certain aspects are concealed due to using caution when saying something, which, ultimately, could be used against the social workers. A direct-indirect struggle deals with the ambiguity of meaning. Here, ambiguity is assisted by disqualification, ${ }^{9}$ which functions as a way to elude or avoid the interplay of the discourses. Disqualification leaves multiple interpretations existing among parties. For example, when describing their work as supporting clients, social workers used vague phrases, such as services necessary for the disability and reasonable compensation. In addition, instead of answering clients' demands, they tell them that the decision needs to be taken to the team for further discussion. In these cases, the exact answer remains unidentified. The following ex- ample illustrates this kind of obscurity: It is unfortunate to go and say that only services necessary for the disability are admitted.

Sometimes the openness-closedness can vary in different themes and can escalate to total closedness, as in leaving the interactional situation. We present the extreme example of segmenting in openness-closedness is excerpt below, in which social worker ceases the interaction by hanging up the phone when the discussion was not progressing:

The client may have experienced that I just hung up the phone - well actually, that is what I did, because the discussion was not leading anywhere. That is what I did. That kind of hostile talk and shouting, no one deserves to hear that. Not [a] social worker or anyone else.

These examples show that the social workers must take caution when interacting with clients. The social workers must be very conscious of the words they use in order to avoid misunderstandings or make promises that may not be followed through. Although Baxter and Montgomery, ${ }^{10}$ positioned the contradiction of openness and closedness under the struggle of expression, in the present study, it was strongly linked to uncertainty in interactional situations and, therefore, positioned under the struggle of certainty.

\section{Discussion}

This study illustrates the relational contradictions of the client-worker relationship in the social services sector, and the results show how discourses compete and are manifested in social workers' talk. The relationship vacillates between the nature of close interpersonal and professional relationships; this is visible in the division between the societal and relational frames, which link to the proximal and distal sites of the utterances. ${ }^{9}$ These intertwined contradictions and their interplay create the meanings of the client-worker relationship in the social workers' talk. The balance between the discourses reflects the degree to which the social workers experience the client-worker relationship as burdensome or satisfactory and how the goal of helping clients is reached.

In our analysis, we arranged the contradictions into societal and relational frames, originating from the nature of social work. The client-worker relationship is a workrelated professional relationship that is not only societally constructed but also reflects features of close interpersonal relationships. The frames describe how our surrounding culture is manifested in interpersonal relationships, as well as how interpersonal relationships maintain and create social order. ${ }^{28}$ Our society creates a frame within which this relationship works by arranging the parties in specific roles; they are positioned in an involuntary asymmetrical relationship but are reciprocally dependent upon each other. The autonomy and dependency in this rela- 
tionship are defined by the structures of the society, which lead to struggles between care and control in the clientworker relationship, as Nijnatten et al. ${ }^{5}$ pointed out. Therefore, our findings authenticate Nijnatten et al.' $\mathrm{s}^{5}$ ideas of tension between care and coercion by showing the kinds of contradictions this tension creates in the client-worker relationship.

The tension between care and control especially reflects in our findings on the contradiction of the ideal and the real. If the expected meanings of this supportive and helping relationship are destroyed in the interaction, the objective of care is easily reframed as control, especially in the clients' point of view. In addition, according to Lloyd et al., ${ }^{1}$ social workers effectively stress the role of conflict between client advocacy and the ability to meet agency needs. Social workers may also feel personally responsible when they fail to help their clients. In addition, our results show that social workers appreciate the fluent process of helping and try to minimize all uncertainty factors and challenges in order to reduce conflict concerning their professionalism. Matthies ${ }^{6}$ questioned whether social work is understandable to those who are outside it; we built on this question and argue that working with these contradictions can make social work difficult even for the social workers themselves. Social workers have a hard time presenting themselves as helpers in controlling and combining the roles of care and control. ${ }^{5}$ With transformative dialogue, in which the competition between the discourses vanishes and discourses are presented as equal, ${ }^{9}$ it may be possible to shift the emphasis from defending actors' positions to a more cooperative standpoint. In that way, the client and the social worker are seen not as opposite poles but as entities that twine together, which subsequently enables the creation of new meanings.

Consequently, it is crucial to highlight the special nature of the client-worker relationship in disability services, including features from close interpersonal and professional relationships, in order to open up new ways to plan and apply communication in social services context. Although client-worker relationships are long-lasting and cover sensitive and personal subjects, they are still workplace relationships that are accompanied by some degree of reservedness. Successful cooperation additionally demands some aspects of closeness. These observations are extremely important, as client work is at the core of social work; a social worker is a key player in supporting disabled clients' welfare in everyday life and in the wider context of improving their inclusion in society.

The theoretical contribution of this study is that it demonstrates the applicability of RDT when studying client-worker relationships in the social services sector. Although RDT has been primarily used to study close private-life relationships, ${ }^{12,13}$ we find that the theory is also applicable for studying contradictions among professional relationships in the social services, since these are workrelated relationships that also possess elements of close interpersonal relationships. In addition, please note that, while this research relies heavily on RDT 2.0 , most research applies the earlier version of this theory, ${ }^{10}$ and only a few studies have observed client-worker interactions in the terms of RDT 2.0. ${ }^{18,19}$ Baxter and Braithwaite ${ }^{29}$ have critiqued existing research for simply identifying dialectical tensions and encouraged adding complexity by looking at how competing discourses interpenetrate to construct meaning in a relationship, which is done in this study. Baxter ${ }^{9}$ also suggested identifying the sites of discursive struggles, which is done here by presenting these discourses in societal and relational frames.

\section{Conclusions}

In the present findings, we have identified multiple contradictions in the client-worker relationship in the social services and emphasized how societal and relational frames of this relationship interpenetrate each other. The present study's results can be used to advance social workers' well-being at work by paying attention to how social workers could manage contradictions in clientworker relationships in terms of the actors' well-being and job satisfaction. The results may also be applied to communication training aimed at helping social workers identify future contradictions in their work. Furthermore, the results increase our understanding of how the clientworker relationship affects job satisfaction, as the results also describe the challenges of making social workers themselves understood. ${ }^{6}$ Overall, if we learn how to manage these tensions to improve well-being, we can also affect the quality of client interactions.

Future studies in this research area should gather data from both parties in the client-worker relationship, such as by conducting observations or paired interviews. It would be interesting to compare the results of this study to studies in which the client is also present in order to determine how contradictions appear in that kind of data. In addition, researchers could use RDT to analyze longitudinal data, which offers a possibility to emphasize also diachronic separation. Cross-sectional studies do not reveal the differences between these diachronic practices and single-voiced monologues. ${ }^{9}$ Researchers could also study, social work tailored toward other than disabled clients to see if we might identify the same kinds of contradictions when observing client-worker relationships.

The societal frame is an important aspect of all clientworker relationships in the social services, and it is important to untangle how that frame affects relational contradictions and the construction of meanings. To improve cooperation, social workers should strengthen the relational frame since the societal frame is beyond each actor's power. However, every interpersonal interaction can also gradually remodel the societal frame, and that is why every meeting and interaction counts. Transparent and open communication about the frames and the con- 
tradictions would increase the mutual understanding of the relationships' context, rights, and duties. Transparent communication can be achieved by being honest and discussing societal problems with clients while simultaneously emphasize the aims of mutual trust and relational integration.

\section{References}

1. Lloyd C, King R, Chenoweth L. Social work, stress and burnout: a review. J Ment Health 2002;11:255-65.

2. Beresford P, Croft S, Adshead L. We don't see her as social worker: a service user case study of the importance of the social worker's relationship and humanity. Brit J Soc Work 2008;38:1388-407.

3. Forrester D, McCambridge J, Waissbein C. Rollnick, S. How do child and family social workers talk to parents about child welfare concerns? Child Abuse Rev 2008;17:23-35.

4. Forrester D, Kershaw S, Moss H, Hughes L. Communication skills in child protection: how do social workers talk to parents? Child Fam Soc Work 2007;13:41-51.

5. Nijnatten C, Hoogsteeder M, Suurmond J. Communication in care and coercion: institutional interaction between family supervisors and parents. Brit J Soc Work 2001;31:705-20.

6. Matthies AL. The otherness of social work under neoliberal governance. Nord Soc Work Res 2013;3:149-58.

7. Beddoe L. Field, capital and professional identity: social work in health care. In: Webb S, eds. Professional identity in social work. Oxon, UK: Routledge; 2017. pp 122-35.

8. Baldschun A, Töttö P, Hämäläinen J, Salo, P. Modeling the occupational well-being of Finnish social work employees: A multigroup confirmatory factor analysis. Hum Serv Org Manage 2016;40:524-39.

9. Baxter LA. Voicing relationships: a dialogic perspective. Los Angeles, CA: Sage; 2011.

10. Baxter LA, Montgomery BM. Relating: dialogues and dialectics. New York, NY: Guilford Press; 1996.

11. Bahtin M. The dialogical imagination: four essays by M. M. Bakhtin. Austin, TX: University of Texas Press; 1981.

12. Baxter LA. Dialectical contradictions in relationship development. J Soc Pers Relat 1990;7:68-88.

13. Baxter LA, Simon E. Relationship maintenance strategies and dialectical contradictions in personal relationships. J Soc Pers Relat 1993;10:225-42.

14. McGuire T, Dougherty TS. "Paradoxing the dialectic": the impact of patients' sexual harassment in the discursive construction of nurses' caregiving roles. Manag Commun Q 2006;19:416-50.
15. Olufowote JO. A dialectical perspective on informed consent to treatment: an examination of radiologists' dilemmas and negotiations. Qual Health Res 2011;21:839-52.

16. Amati R, Hannawa A. Relational dialectics theory: disentangling physician-perceived tensions of end-of-life communication. Health Commun 2014;29:962-73.

17. Dean M, Oetzel J. Physicians' perspectives of managing tensions around dimensions of effective communication in the emergency department. Health Commun 2014;29:257-66.

18. O'Hara LL, Shue CK. Discourses of diabetes management in patient-physician interactions. The Qual Rep 2018;23: 1282-300.

19. Peltola M, Isotalus P. Competing discourses of professionalpatient relationships in type 2 diabetes management. Health Commun 2019;1-10. doi: 10.1080/10410236.2019.1663586.

20. Suter EA, Baxter LA, Seurer LM, Thomas LJ. Discursive constructions of the meaning of "family" in online narratives of foster adoptive parents. Commun Monogr 2014;81:59-78.

21. Thomas LJ, Scharp KM. "A family for every child": discursive constructions of "ideal" adoptive families in online foster adoption photolistings that promote adoption of children from foster care. Adopt Q 2017;20:44-64.

22. Thomas LJ, Jackl JA, Crowley JL. "Family? ... not just blood": discursive constructions of "family" in adult, former foster children's narratives. J of Fam Commun 2017;3:238-53.

23. Baxter LA. Relationships as dialogues. Pers Relationships 2004;11:1-22.

24. The Ministry of Social Affairs and Health. Services and support for people with disabilities. 2018. Available from: https://stm.fi/en/disability-services.

25. Kvale S. Interviews: An introduction to qualitative research interviewing. Thousand Oaks, CA: Sage; 1996.

26. Braun V, Clarke V. Using thematic analysis in psychology. Qual Res Psychol 2006;3:77-101.

27. TENK. Ethical principles of research in the humanities and social and behavioural sciences and proposals for ethical review. Helsinki; 2009. Available from: http://www.tenk.fi/ sites/tenk.fi/files/ethicalprinciples.pdf

28. Baxter, LA, Asbury, B. Critical approaches to interpersonal communication: charting a future. In: Braithwaite DO, Schrodt P, eds. Engaging theories in interpersonal communication. 2nd ed. Thousand Oaks, CA: Sage; 2015. pp 185-97.

29. Baxter LA, Braithwaite DO. Relational dialectics theory: crafting meaning from competing discourses. In: Braithwaite DO, Baxter LA, eds. Engaging theories in interpersonal communication: multiple perspectives. Thousand Oaks, CA: Sage; 2008. pp 349-362. 